\title{
Improving surface temperature measurement of the power cable and insulated busbar using the heat insulated layer
}

\author{
Liezheng TANG*, Jiangjun RUAN*, Guannan LI* and Xuefeng YIN* \\ ${ }^{*}$ School of Electrical Engineering and Automation, Wuhan University \\ Wuhan 430072, China \\ E-mail: tlz9302@163.com
}

Received: 27 September 2019; Revised: 26 December 2019; Accepted: 14 January 2020

\begin{abstract}
The surface temperature measurement is susceptible to the surrounding air for the cable or the insulated busbar laid in free air. Therefore, an approach for improving their surface temperature measurements by covering the temperature sensor with a heat insulated layer is put forward. Firstly, the surface temperatures of the cable and the insulated busbar attached by a platinum resistance thermometer with and without a heat insulated layer under rated current are obtained using the thermal analyses in Comsol. Subsequently, the temperature rise test of the insulated busbar was carried out for the indirect verification of the previous analyses. The measured surface temperatures were used to calculate the conductor temperature based on the transient thermal network. By comparison with the measured conductor temperature, it is found that the deviation of the surface temperature measurement without the heat insulated layer is about $4 \sim 7 \mathrm{~K}$ while that with the heat insulated layer is only $\pm 1 \mathrm{~K}$. Further, the generalization of the presented method to the distributed temperature sensing system is analyzed. This study demonstrates that the accuracy of the surface temperature measurement of the cable and the insulated busbar can be effectively improved by wrapping a suitable heat insulated layer around the sensor.
\end{abstract}

Keywords : Power cable, Insulated busbar, Temperature measurement, Thermal analysis, Indirect verification

\section{Introduction}

Cable should transfer power at maximum current carrying capacity without exceeding permissible limits (IEC 60287, 1982). This current is affected by not only cable design parameters but also the surrounding thermal environment which is usually time-varying. Typical ampacity limits normally take into consideration the generalized and assumed worst expected conditions. A temperature monitoring system, appropriately applied, provides real-time temperature information to the user that permit adjusting the current limits for both continuous and emergency conditions (IEEE Standard 1718, 2012). The best and most accurate thermal rating is based on direct monitoring of the conductor temperature under load, but for practical reasons, this is difficult to perform when the cable is energized. Besides, the direct approach is not feasible for existing cables without a built-in temperature sensor before. Hence, it is more usual to measure the cable surface temperature and then to indirectly calculate the conductor temperature from this (Swingler and Holte, 1994).

There has been extensive research regarding the real-time calculation of cable conductor temperature using the surface temperature and the load current, including the thermal network (Jones et al., 2004; Millar and Lehtonen, 2005; Yang et al., 2018), the finite element method (FEM) (Li et al., 2006) and the artificial intelligence algorithms (Niu et al., 2016). Since the approach for conductor temperature calculation is quite mature, the validity of the model depends principally on the reliability of the cable thermal parameters and the inputs. As one of the most important inputs in the calculation model, the surface temperature measurement has a profound effect on the accuracy of the algorithm. For the cable laid in free air (cable in tunnel, for example), if the temperature sensor is directly attached on the cable surface, the temperature of the sensor is actually affected by both the surface temperature and ambient temperature. That is to say, the measured value will be lower than the real cable surface temperature. To the best of our knowledge, such 
problem has not yet been thoroughly discussed and verified.

Apart from the power cable, the insulated busbar is another common power transmission line which is similar in structure to the cable (Li et al., 2018; Hu et al., 2013; Li et al., 2018). The main differences between them lie in that the insulated busbar may be installed outdoors and its conductor is a hollow conductor rather than the stranded one.

To overcome the impact of the ambient temperature, the surface temperature measurement of the power cable and the insulated busbar is improved by coating the temperature sensor with a heat insulated layer in this paper. In the following passage, the FEM thermal analyses of the insulated busbar and the cable with the temperature sensor directly laid on the surface were first carried out. Afterwards, a heat insulated layer was added into the previous FEM model to illustrate the function of the heat insulated layer. Furthermore, the temperature rise test of an insulated busbar was performed to verify the role of the heat insulated layer in surface temperature measurement.

\section{FEM thermal analysis}

\subsection{The cases with only the temperature sensor laid on the surface}

\subsubsection{The insulated busbar}

A $10 \mathrm{kV}$ insulated busbar is taken as an example. It is assumed that the busbar is long enough and laid in free air. The ambient temperature is set to $25^{\circ} \mathrm{C}$ and the rated current of $1350 \mathrm{~A}$ is injected into the busbar route. A cylindrical platinum resistance thermometer with a diameter of $2.5 \mathrm{~mm}$ and a length of $20 \mathrm{~mm}$ is adopted as the temperature sensor attached on the busbar surface.

The structure of the insulated busbar in this paper is depicted in Fig. 1. The insulation consists of two parts, Polytetrafluoroethylene (PTFE) layer and Cross-linked polyethylene (XLPE) layer. Conductive grading layers are embedded during the wrapping in the PTFE insulation for the field control. These conductive grading layers can be neglected in the heat-transfer process due to their extremely small thickness. The aluminum earth sheath ensures safety for both personnel and the measuring devices. Since the hollow copper conductor is closed at both ends, there is little convective heat transfer inside the conductor. As a result, only heat conduction is considered in the thermal analysis. The dimensions and the thermal parameters of each layer are provided in Table 1 (IEC 60853, 1989; Price et al., 2002; Blumm et al., 2010). The temperature coefficient of resistance of copper is about $0.00393 / \mathrm{K}$ at $20^{\circ} \mathrm{C}$ (Dellinger et al., 1910 ) and this temperature-dependent power loss in the conductor is considered in the model.

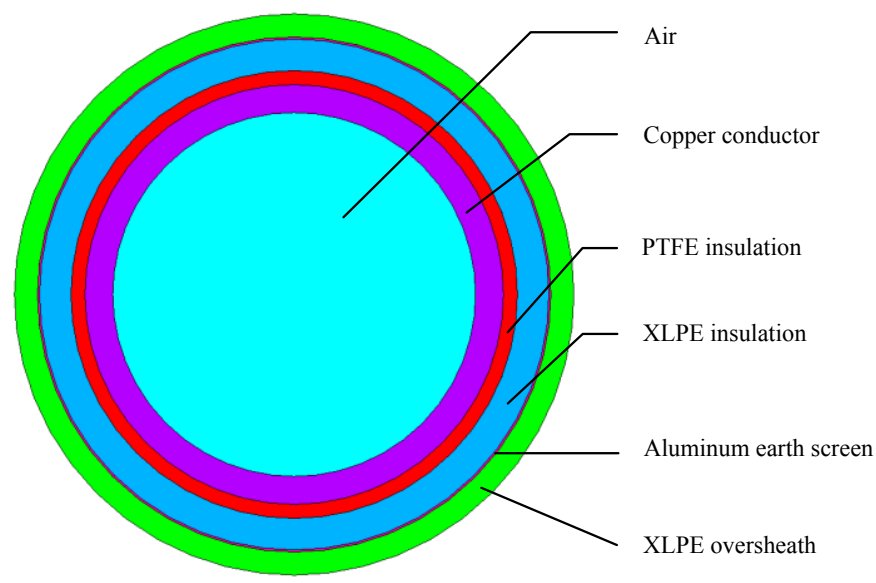

Fig. 1. The structure of the insulated busbar.

Table 1 The structural and thermal parameters of the insulated busbar.

\begin{tabular}{cccc}
\hline Components & External radius $(\mathrm{mm})$ & Thermal conductivity $(\mathrm{W} /(\mathrm{m} \cdot \mathrm{K}))$ & Volumetric specific heat $\left(\mathrm{MJ} /\left(\mathrm{m}^{3} \cdot \mathrm{K}\right)\right)$ \\
\hline Air & 26 & 0.023 & 1.3 \\
Copper conductor & 30 & 383 & 3450 \\
PTFE insulation & 32 & 0.259 & 2290 \\
XLPE insulation & 36.5 & 0.286 & 2400 \\
Aluminum sheath & 36.8 & 218 & 2500 \\
XLPE oversheath & 40.1 & 0.286 & 2400 \\
\hline
\end{tabular}


In order to analyze the temperature of the sensor laid on the insulated busbar, a 3-D calculation model given in Fig. 2 is established by Comsol.

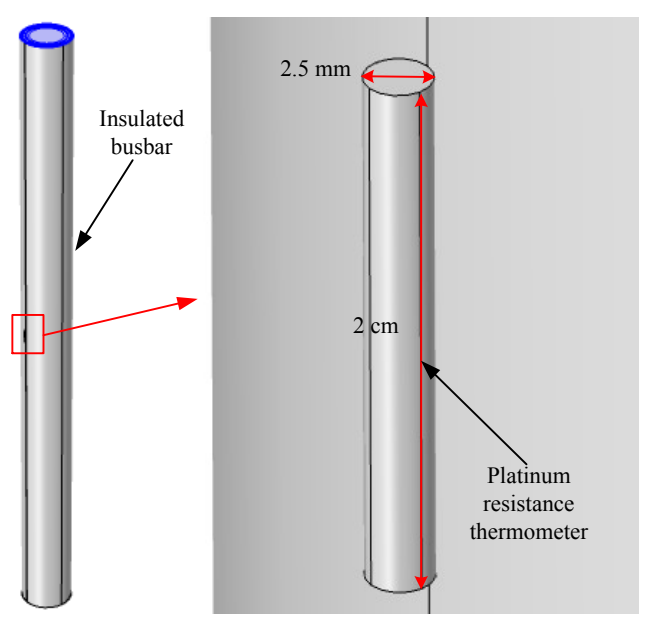

Fig. 2. The calculation model for FEM thermal analysis of the insulated busbar laid with the platinum resistance thermometer.

The axial length of the insulated busbar is taken as $1 \mathrm{~m}$, and the surface of the insulated busbar is tangent to that of the sensor to simulate the mutual contact. The platinum resistance thermometer is principally composed of platinum wire, alumina ceramic and metal protective sheath (IEC 60751, 2016). Since the platinum wire and the protective sheath are fairly thin, the thermal conductivity of the whole sensor can be simply regarded as that of the alumina ceramic, about $36 \mathrm{~W} /(\mathrm{m} \cdot \mathrm{K})$ (Gengel, 2008).

Without considering the solar radiation and the wind, the boundary of the outer surface shown in silver color in Fig. 2 satisfies combined convection and radiation condition, which can be expressed as (Gengel, 2008)

$$
-\lambda \frac{\partial T}{\partial n}=h\left(T_{\infty}-T\right)+\varepsilon \sigma\left(T_{\infty}^{4}-T^{4}\right)
$$

where $T_{\infty}$ and $T$ are the ambient temperature and surface temperature, respectively. $h$ is the convection heat transfer coefficient and $\varepsilon$ is the emissivity of the surface, usually set to 0.95 for the oversheath (Tanaskovic, 2018 ). $\sigma=5.67 \times 10^{-8}$ $\mathrm{W} / \mathrm{m}^{2} \cdot \mathrm{K}^{4}$ is the Stefan-Boltzman constant. The first term on the right side of the Eq. (1) represents the convective heat transfer between the surface and air while the second one is the surface-to-ambient radiation.

The convective heat transfer coefficient depends greatly on the variation of temperature and geometry of the surface as well as its orientation and the thermophysical properties of the air. The complexities of air motion make it quite difficult to obtain simple analytical relations for convective heat transfer coefficient, but fortunately, there are some empirical correlations for the average convective heat transfer coefficient. The insulated busbar is representative of a horizontal cylinder, of which the convective heat transfer coefficient is expressed as (Gengel, 2008)

$$
h=\left\{0.6+\frac{0.387 \mathrm{Ra}^{1 / 6}}{\left[1+(0.599 / \mathrm{Pr})^{9 / 16}\right]^{8 / 27}}\right\}^{2} \lambda / L
$$

where $L$ is the diameter of the cylinder, $\mathrm{m}$ and $\operatorname{Pr}$ is the Prandtl number of air, almost 0.73 in the temperature range from 10 to $40^{\circ} \mathrm{C}$ (Gengel, 2008). Ra is the Rayleigh number, which is

$$
\mathrm{Ra}=\frac{g \beta\left(T-T_{\infty}\right) L^{3} \operatorname{Pr}}{v^{2}}
$$

where $g$ is gravitational acceleration, roughly $10 \mathrm{~m} / \mathrm{s}^{2} ; \beta$ is coefficient of volume expansion, $1 / \mathrm{K}$, which is equal to $1 / \mathrm{T}$ for the air; $v$ is the kinematic viscosity of the air, nearly $1.85 \times 10^{-5} \mathrm{~W} / \mathrm{m}^{2} \cdot \mathrm{K}^{4}$ between 10 and $40^{\circ} \mathrm{C}(\mathrm{Gengel}, 2008)$.

On the end faces of the insulated busbar as shown in blue color in Fig. 2, the axial heat flow can be considered to be zero and its boundary satisfies adiabatic condition, which is 


$$
-\lambda \frac{\partial T}{\partial n}=0
$$

For the steady-state heat conduction problem with constant thermal conductivity, its governing equation is as follows

$$
\frac{\partial^{2} T}{\partial x^{2}}+\frac{\partial^{2} T}{\partial y^{2}}+\frac{\partial^{2} T}{\partial z^{2}}+\frac{q}{\lambda}=0
$$

where $q$ is the heat generation rate per unit volume.

The method to solve the governing equation is FEM, the most widely used method for solving heat conduction. The typical work out of FEM involves: (1) dividing the domain of the problem into a collection of subdomains, with each subdomain represented by a set of element equations to the original problem, followed by (2) recombining all sets of element equations into a global system of equations for the final calculation.

FEM is increasingly adopted by lots of commercial software, such as Ansys and Comsol, etc. Since Comsol can easily handle the combined convection and radiation condition, the thermal analyses were performed using Comsol.

The steady-state temperature profile of the insulated busbar is shown in Fig. 3a. As can be seen from the figure, the temperature of the sensor is significantly lower than the neighboring surface temperature of the insulated busbar. The axial surface temperature along the intersecting line between the sensor and the busbar is depicted in Fig. 3b. The surface temperature of the insulated busbar is about $43.4^{\circ} \mathrm{C}$ while the temperature of the sensor is only $37.7^{\circ} \mathrm{C}$. That is to say, the temperature measurement deviation is roughly $5.7 \mathrm{~K}$ in this case. This is because that the temperature sensor is in direct contact with both the surface and the open air. On the one hand, the sensor absorbs the heat from the busbar surface, and on the other hand, the sensor dissipates heat to the surrounding air. This is equivalent to increasing the heat dissipation of the surface, thus causing a lower measuring value than the real surface temperature.

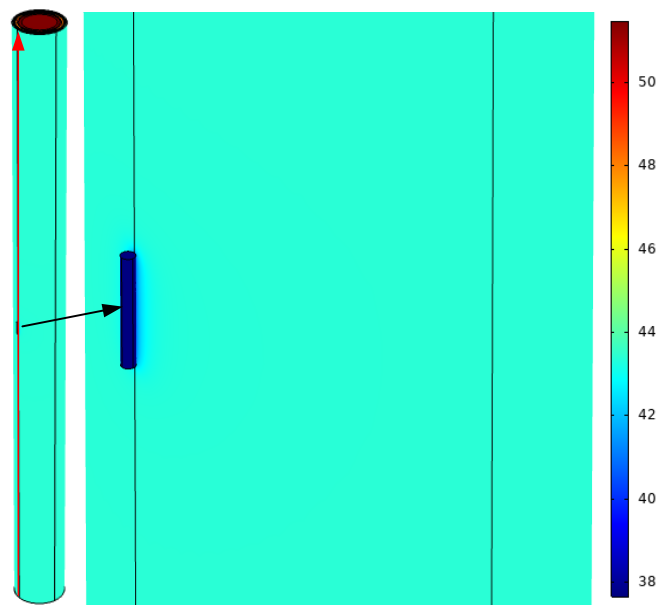

(a)

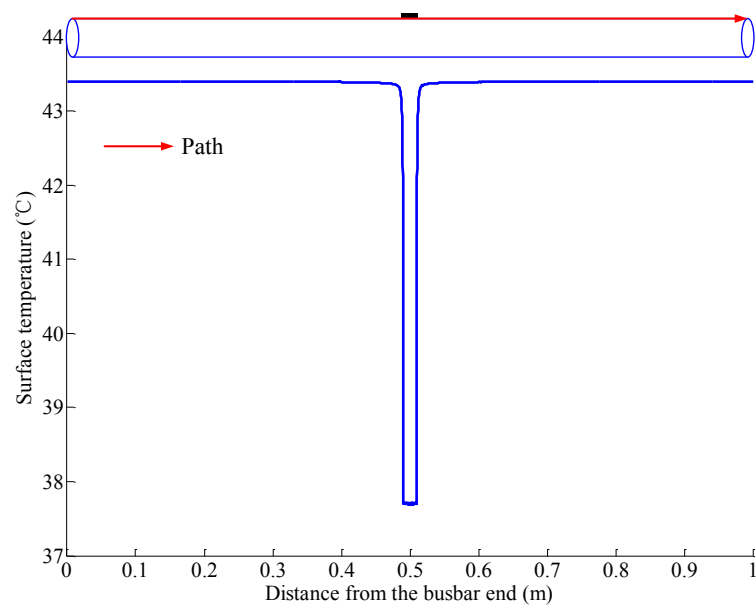

(b)

Fig. 3. The temperature of the insulated busbar laid with the platinum resistance thermometer. (a) Overall temperature profile. (b) The surface temperature along the platinum resistance thermometer.

\subsubsection{The power cable}

The thermal analysis of a $110 \mathrm{kV}$ cable is performed in the same way as previously described. The structural and thermal parameters of this power cable are given in Table 2 (IEC 60853, 1989).

It is assumed that the rated current of $1080 \mathrm{~A}$ is injected into the cable route and the other simulation conditions are all the same to that of the insulated busbar.

The simulation results are illustrated in Fig. 4. It can be observed that the temperature of the platinum resistance thermometer is about $3.4 \mathrm{~K}$ lower that the cable surface temperature and this deviation is less than that of the insulated busbar, $5.7 \mathrm{~K}$. This is because that surface temperature of the cable is lower than that of the insulated busbar. Accordingly, the absolute measurement deviation of the platinum resistance thermometer becomes lower. However, if the relative deviation is considered, these two measurement deviation will be nearly the same. For the insulated busbar, 
the surface temperature rise above the ambient temperature is $18.4 \mathrm{~K}$ and the measurement deviation is about $5.7 \mathrm{~K}$. In the case of the cable, the surface temperature rise and the absolute deviation are $10.8 \mathrm{~K}$ and $3.4 \mathrm{~K}$, respectively. Both the ratios of absolute deviation and the surface temperature are nearly $31 \%$, which demonstrates that the absolute measurement deviation of the surface temperature is approximately proportional to the surface temperature rise.

Table 2 The structural and thermal parameters of the power cable.

\begin{tabular}{cccc}
\hline Components & External radius $(\mathrm{mm})$ & Thermal conductivity $(\mathrm{W} /(\mathrm{m} \cdot \mathrm{K}))$ & Volumetric specific heat $\left(\mathrm{MJ} /\left(\mathrm{m}^{3} \cdot \mathrm{K}\right)\right)$ \\
\hline Copper conductor & 15 & 383 & 3450 \\
XLPE insulation & 34 & 0.286 & 2400 \\
Water barrier & 37.2 & 0.167 & 2000 \\
Aluminum sheath & 39.3 & 218 & 2500 \\
XLPE oversheath & 49 & 0.286 & 2400 \\
\hline
\end{tabular}

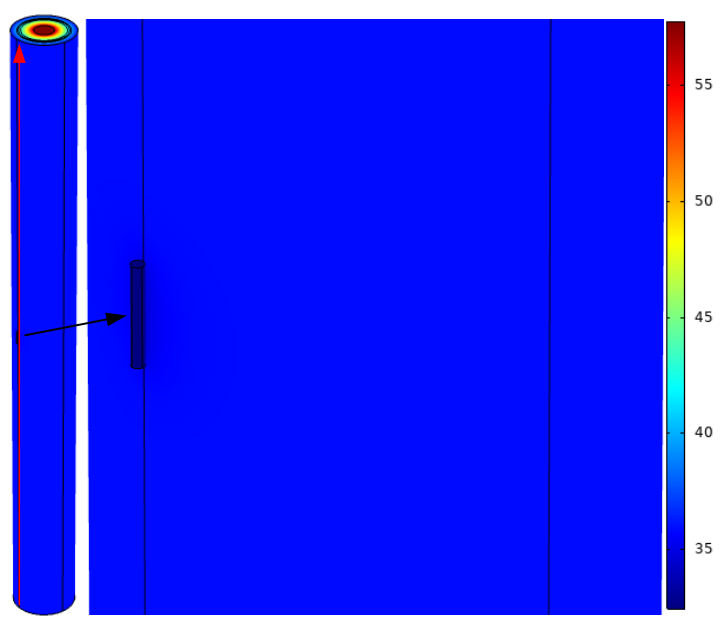

(a)

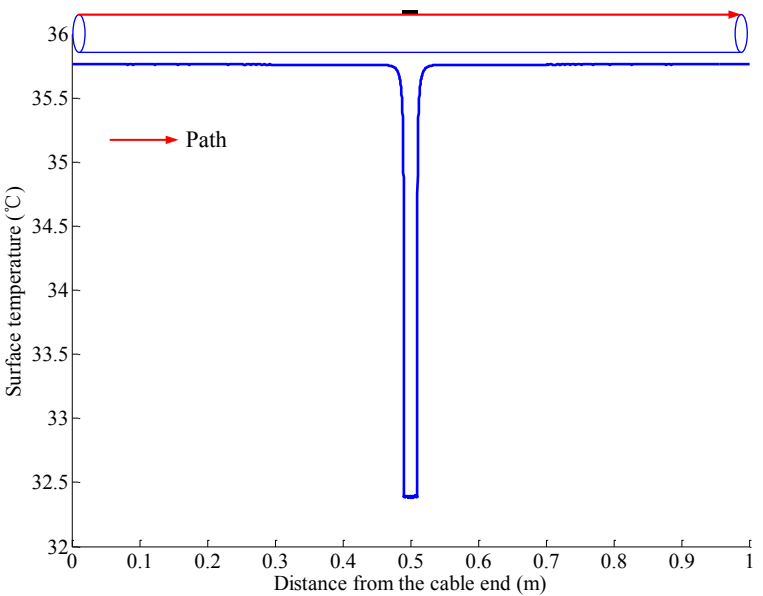

(b)

Fig. 4. The temperature of the power cable laid with the platinum resistance thermometer. (a) Overall temperature profile. (b) The surface temperature along the platinum resistance thermometer.

\subsection{The cases with the temperature sensors covered by a heat insulated layer}

The local thermal network around the temperature sensor is shown in Fig. 5a. The temperature sensor is equivalent to increasing the heat dissipation area of the surface, thus reducing the external thermal resistance $R_{\mathrm{e}}$. Since the temperature of the sensor is the product of the heat flow and the external thermal resistance $R_{\mathrm{e}}$, the decreasing external thermal resistance $R_{\mathrm{e}}$ will result in a decrease in the temperature of the sensor.

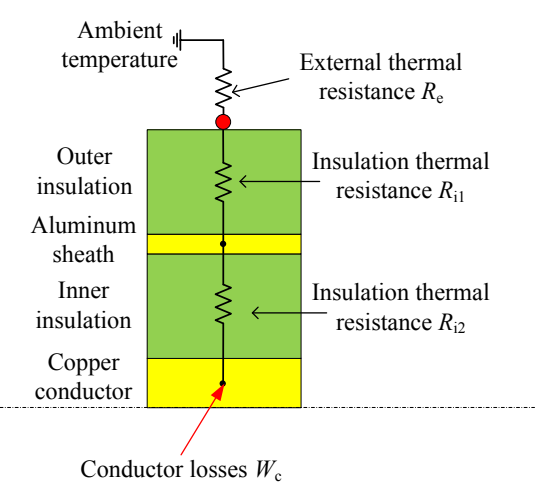

(a)

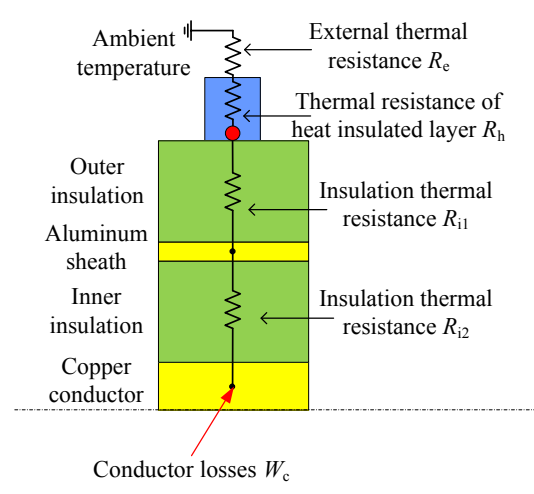

(b)

Fig. 5. The local thermal network of the insulated busbar laid with the temperature sensor. (a) Without the heat insulated layer. (b) With the insulated layer. 
In order to compensate for the decrease in external thermal resistance $\Delta R_{\mathrm{e}}$, this paper adopted a heat insulated layer to wrap the sensor, thereby increasing the thermal resistance between the sensor and the air, as shown in Fig. $5 \mathrm{~b}$. If the thermal resistance of the heat insulated layer $R_{\mathrm{h}}$ is equal to the decrease in external thermal resistance $\Delta R_{\mathrm{e}}$, it is expected that the measurement error will be greatly reduced.

\subsubsection{The insulated busbar}

In this paper, the foam rubber is taken as the heat insulated layer to wrap around the sensor. The measured value of the thermal conductivity in the foam rubber is $0.043 \mathrm{~W} /(\mathrm{m} \cdot \mathrm{K})$. The width of the heat insulated layer is specified to 3 $\mathrm{cm}$, slightly larger than the sensor so as to ensure that the temperature sensor can be completely covered. The thickness of the heat insulated layer has a great influence on the temperature of the sensor. The relationship between the thickness of the heat insulated layer and the temperature of the sensor is shown in Fig. 6.

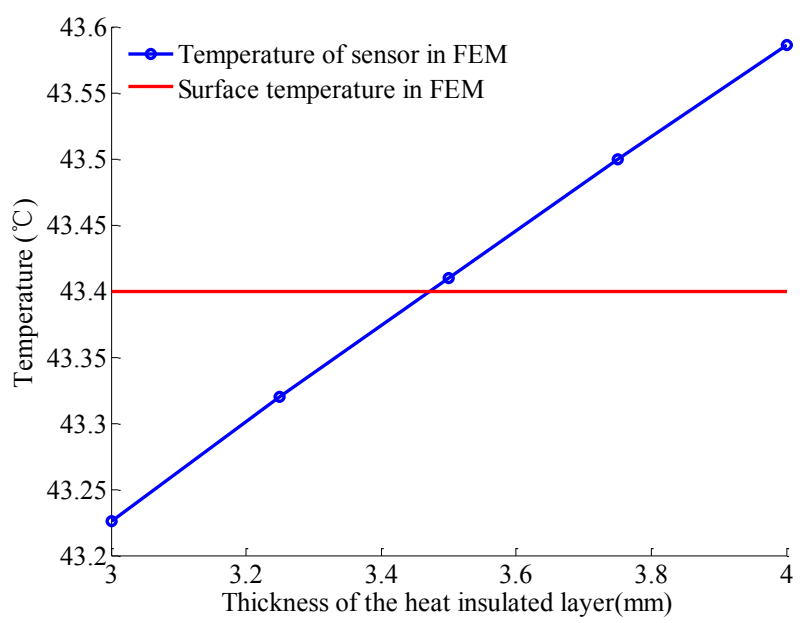

Fig. 6. The relationship between the thickness of the heat insulated layer and the temperature of the sensor in the insulated busbar.

It can be seen from Fig. 6 that when the thickness is between $3 \mathrm{~mm}$ and $4 \mathrm{~mm}$, the measurement deviation is no more than $0.2 \mathrm{~K}$, which meets the requirements of engineering errors. For convenience, the thickness of the heat insulated layer is chosen to be $4 \mathrm{~mm}$ for the insulated busbar in this paper. The calculation model and results with the thickness of $4 \mathrm{~mm}$ are shown in Fig. 7 and Fig. 8, respectively. It can be clearly found that the surface temperature measurement accuracy is appreciably improved after using the heat insulated layer with the absolute deviation of less than $0.1 \mathrm{~K}$.

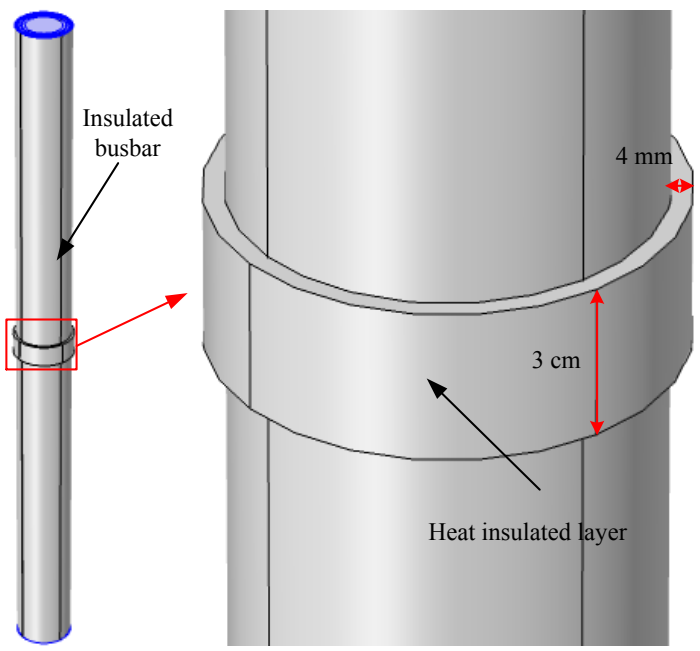

Fig. 7. The calculation model for FEM thermal analysis of the insulated busbar laid with the platinum resistance thermometer covered by the optimal heat insulated layer. 


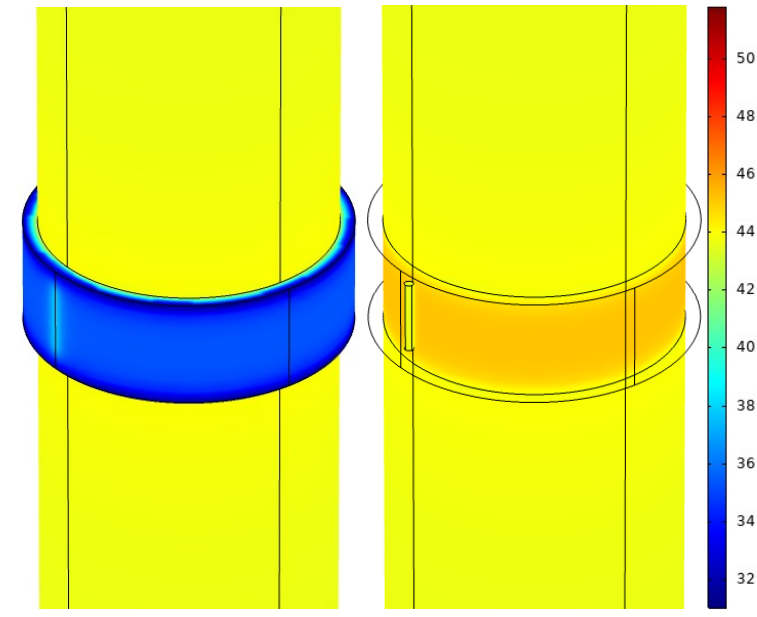

(a)

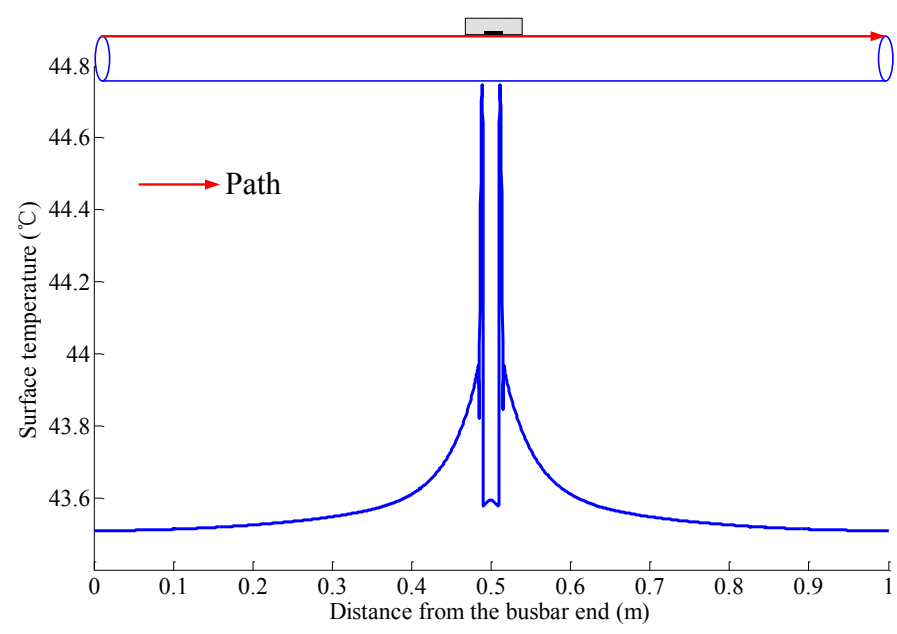

(b)

Fig. 8. The temperature of the insulated busbar laid with the platinum resistance thermometer covered by a heat insulated layer. (a) Overall temperature profile. (b) The surface temperature along the platinum resistance thermometer.

\subsubsection{The power cable}

The temperature sensor is also wrapped with the heat insulated layer for the power cable in the thermal analysis model. The relationship between the thickness of the heat insulated layer and the temperature of the sensor is shown in Fig. 9. For the power cable, even when the thickness of the heat insulated layer is $2.6 \mathrm{~mm}$, which is very close to the diameter of the sensor, the measured temperature is still slightly higher than the surface temperature. For convenience, the thickness of the heat insulated layer is chosen to be $3 \mathrm{~mm}$ with the measurement deviation less than $0.2 \mathrm{~K}$, and its calculation results are shown in Fig. 10.

It is found that the thickness of the heat insulated layer is different between the power cable and the insulated busbar. This phenomenon can be explained by the thermal network. Because of the thermal resistance of heat insulated layer, the temperature of conductor under the heat insulated layer is higher than the surrounding conductor temperature. Therefore, in the sections within the heat insulated layer, some heat flow in the radial direction will be transferred in the axial direction along the conductor and sheath. Obviously, the more the axial heat flow, the less the radial heat flow and the lower the temperature of the sensor. Because the insulation thermal resistance of the insulated busbar is less than that of the cable, the heat flow in the axial direction will be greater under the same heat insulated layer, thus leading to the lower temperature of sensor for the insulated busbar. That is to say, the heat insulated layer of the insulated busbar should be thicker than that of the cable.

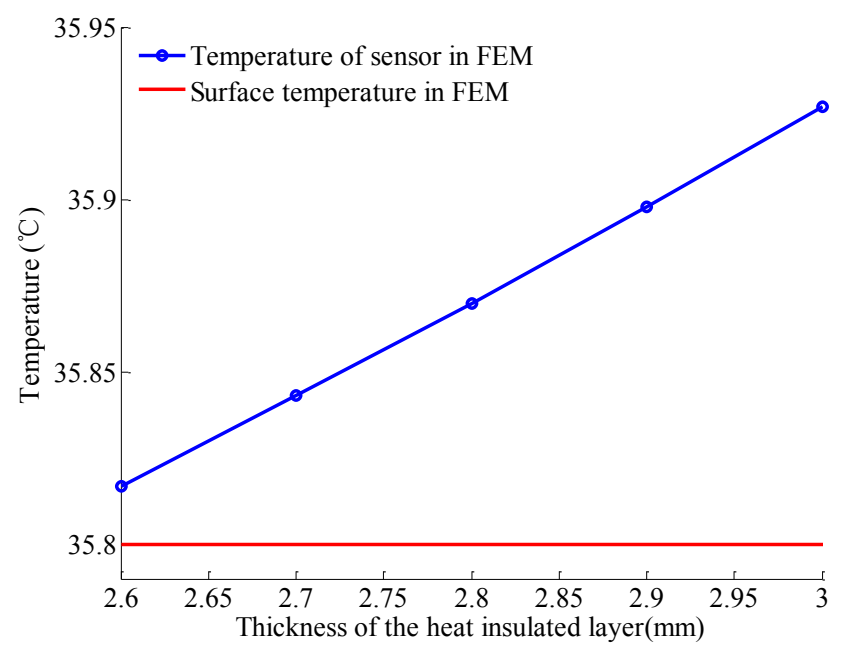

Fig. 9. The relationship between the thickness of the heat insulated layer and the temperature of the sensor in power cable. 

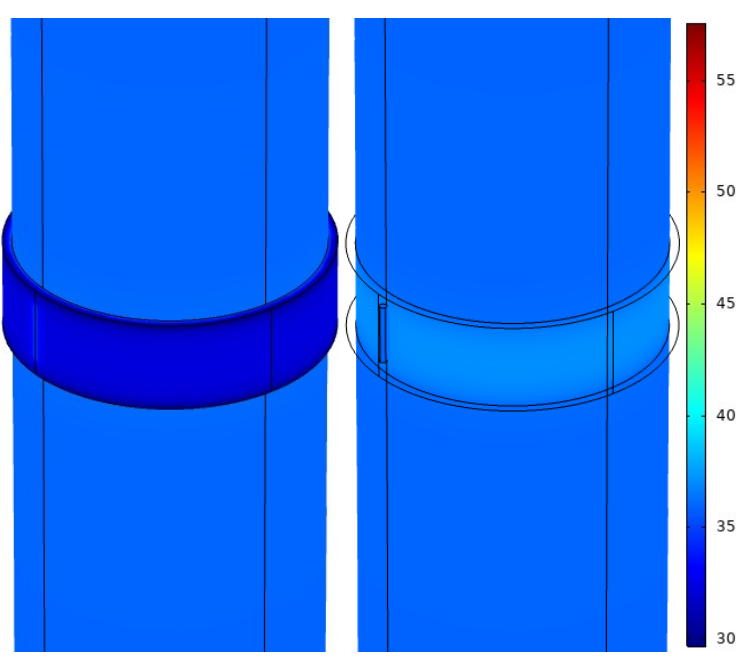

(a)

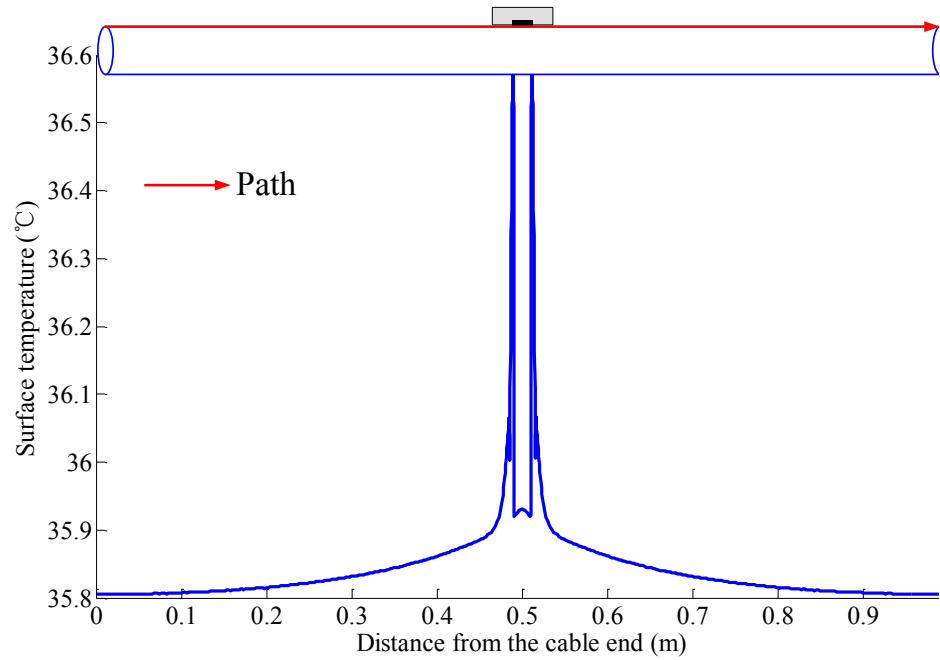

(b)

Fig. 10. The temperature of the power cable laid with the platinum resistance thermometer covered by a heat insulated layer. (a) Overall temperature profile. (b) The surface temperature along the platinum resistance thermometer.

\subsubsection{The effect of ambient temperature}

Since the ambient temperature has a certain effect on the convection and radiation heat transfer, it is necessary to study the influence of the ambient temperature on the measurement accuracy.

For this reason, several FEM thermal analyses were carried out at various ambient temperatures under the rated load current using the above optimized heat insulated layers. The comparison of the temperature between the sensor and the surface is illustrated in Table 3 . It can be seen that when the ambient temperature is within the range of -40 to $50^{\circ} \mathrm{C}$, the measurement deviation is basically within $\pm 0.2 \mathrm{~K}$, indicating the wide applicability of the optimized heat insulated layer thickness.

Table 3 The comparison of the temperature between the sensor and the surface at various ambient temperatures.

\begin{tabular}{|c|c|c|c|c|c|c|c|c|c|c|c|}
\hline Ambic & t temperature $\left({ }^{\circ} \mathrm{C}\right)$ & -40 & -30 & -20 & -10 & 0 & 10 & 20 & 30 & 40 & 50 \\
\hline \multirow{3}{*}{ Insulated busbar } & Surface temperature $\left({ }^{\circ} \mathrm{C}\right)$ & -21.2 & -11 & -0.9 & 9.1 & 19 & 28.8 & 38.6 & 48.4 & 58.1 & 67.8 \\
\hline & Measured temperature $\left({ }^{\circ} \mathrm{C}\right)$ & -21.4 & -11.2 & -1.1 & 8.9 & 18.9 & 28.8 & 38.7 & 48.5 & 58.3 & 68 \\
\hline & Temperature deviation $(\mathrm{K})$ & -0.2 & -0.2 & -0.2 & -0.2 & -0.1 & 0 & 0.1 & 0.1 & 0.2 & 0.2 \\
\hline \multirow{3}{*}{ Power cable } & Surface temperature $\left({ }^{\circ} \mathrm{C}\right)$ & -28.8 & -18.7 & -8.7 & 1.2 & 11.1 & 21 & 30.9 & 40.7 & 50.5 & 60.3 \\
\hline & Measured temperature $\left({ }^{\circ} \mathrm{C}\right)$ & -28.9 & -18.8 & -8.8 & 1.2 & 11.1 & 21.1 & 31 & 40.9 & 50.7 & 60.5 \\
\hline & Temperature deviation (K) & -0.1 & -0.1 & -0.1 & 0 & 0 & 0.1 & 0.1 & 0.2 & 0.2 & 0.2 \\
\hline
\end{tabular}

\section{Verification test}

\subsection{General consideration}

To verify the role of the heat insulated layer in the surface temperature measurement, it is necessary to carry out the temperature rise test on the actual cable or insulated busbar. During the test, two sets of temperature sensors are used to measure the surface temperature and one set of the sensors are covered with the heat insulated layer for comparison. However, it will be hard to directly judge which set of sensors is more accurate as the real surface temperature is virtually unknown. For this reason, the indirect verification is resorted to in this paper. As mentioned in the Introduction section, the real-time conductor calculation based on the surface temperature and load current is feasible provided that the thermal properties are known and the surface temperature can be measured with reasonable accuracy. That is to say, if the surface temperature accuracy is high, the calculated conductor temperature should be close enough to the measured value, and vice versa.

There are two difficulties in using the power cable as the test object. The first one is that the thermal resistance of the air gap between the water barrier and metal shield is hard to determine (Yang et al., 2018), which will introduce a 
large systematic deviation in the calculation model. The second one is that the cable conductor temperature can hardly be accurately measured. Since the cable conductor is solid, one must drill a small hole in the cable and then insert the sensor into the hole. In this case, the cable temperature distribution around the sensor will differ from the original one due to the destruction of the cable. Moreover, only part of the temperature sensor is in contact with the conductor so that the temperature of the sensor will be lower than the conductor temperature.

Fortunately, the insulated busbar can satisfactorily overcome the above difficulties. There is no air gap between any layers inside the busbar and the thermal parameters of each layer are easy to determine. The conductor of the insulated busbar is hollow so that the temperature sensor could be threaded through the conductor from one end of the busbar to the inside. In this way, the temperature profile can hardly be changed. At the same time, since the inner surface of the conductor is isothermal, the measurement deviation of the temperature sensor will be minimized in this way.

\subsection{Conductor temperature calculation model}

The cable conductor temperature calculation is usually based on the thermal network recommended by IEC 60853 (IEC 60853, 1989). The insulated busbar can also refer to the similar approach. The main difference is that there is air inside the conductor for the insulated busbar. Since the inner surface of the conductor is isothermal, there is almost no temperature gradient inside. Hence, the convective heat transfer is negligible. Meanwhile, because the temperature difference of the air is fairly small, the corresponding thermal resistance of the air is almost zero. Also, the air density is much smaller than the solid, so that the thermal capacitance of the air is ignorable. In conclusion, the internal air can be completely ignored in the thermal network of the insulated busbar, as shown in Fig. 11.

The calculation of the thermal resistances and capacitances is given in IEC 60853 (IEC 60853, 1989). The dimensions and material parameters of each layer are shown in Table 1.

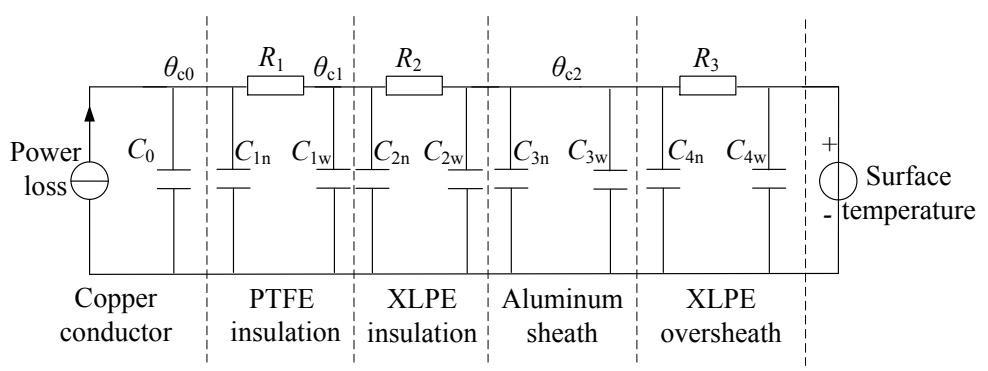

Fig. 11. Transient thermal network of the insulated busbar as per IEC 60853.

\subsection{Experimental setup}

According to the above analysis, the temperature rise test platform for the insulated busbar was built up, as presented in Fig. 12.

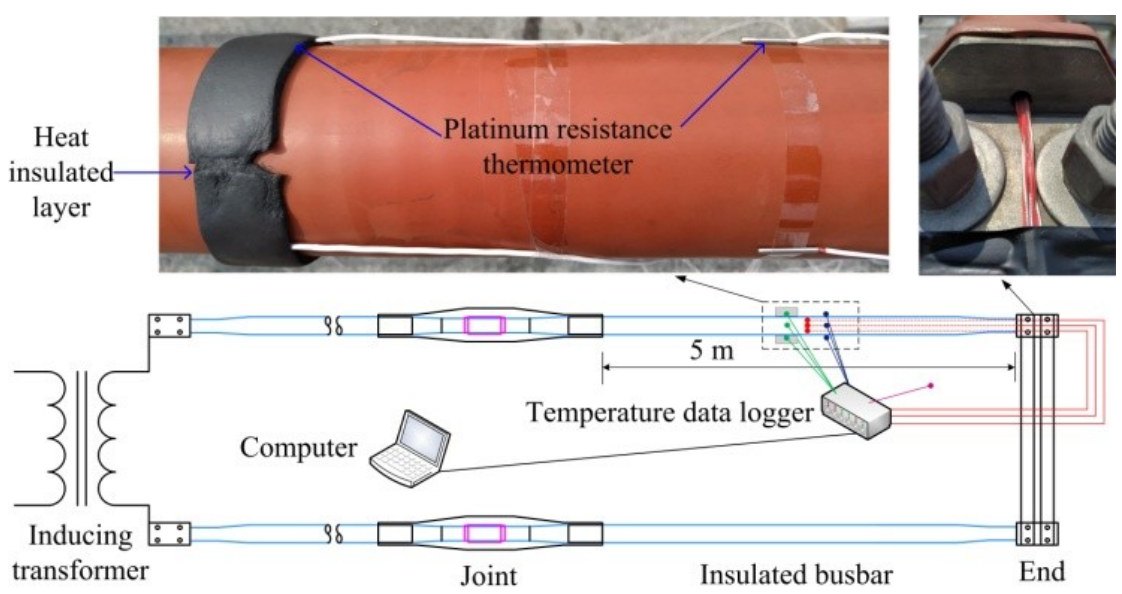

Fig. 12. The arrangement of temperature rise test of the insulated busbar. 
The structure and material of the test insulated busbar are exactly the same as described in Section 2.1.1. A single busbar is $5 \mathrm{~m}$ long so that the middle part of the busbar is thermally independent of both the joint and end. Two sets of platinum resistance thermometers with tolerance class of A (IEC 60751, 2016). were placed on the outer surface in the middle part of the busbar to measure the surface temperature. Each set had three sensors evenly arranged in the circumferential direction at the same axial position to reduce the random measurement deviation by averaging. One set of the sensors was wrapped with a foam rubber with a width of $3 \mathrm{~cm}$ and a thickness of $4 \mathrm{~mm}$ while the other was only fixed with a transparent tape without the heat insulated layer. Besides, a hole was drilled at one end of the busbar and another three temperature sensors were threaded from this hole to measure the conductor temperature in the middle part of the busbar. Another temperature sensor is suspended in the air for ambient temperature measurement. During the whole test, the load current generated by the inducing transformer was constant, 1350 A throughout the test.

\section{Results and discussion}

\subsection{Constant load current}

\subsubsection{Experimental results}

The collection of raw test data began at 12 noon on May 30th, 2019 and the measured temperatures are illustrated in Fig. 13. Since the insulated busbar was installed outdoors, the measured temperatures were readily affected by the weather. The first day was cloudy, so all the measured temperatures were almost constant. The remaining four days were sunny so that all the temperatures varied markedly with time although the current remained unchanged at $1350 \mathrm{~A}$.

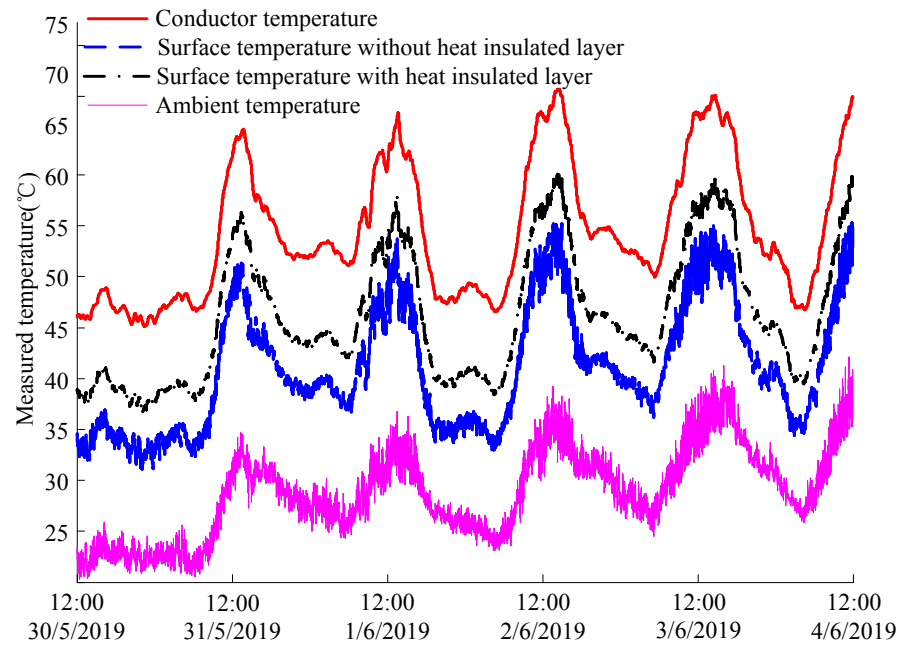

Fig. 13. The measured temperatures during the test.

\subsubsection{Validation of the approach}

Based on the measured surface temperatures and current, the conductor temperatures were calculated for the indirect verification. The comparison between the calculated and measured results is given in Fig. 14. It can be observed that the calculated temperature using surface temperature with the heat insulated layer is in good agreement with the measured value with absolute deviation of about $\pm 1 \mathrm{~K}$. However, the calculated result based on the surface temperature without heat insulated layer is lower by $4 \sim 7 \mathrm{~K}$. This comparison convincingly justifies the role of the heat insulated layer in the surface temperature measurement.

According to the previous FEM thermal analysis in Section 2.1.1, the measurement deviation is about $5.7 \mathrm{~K}$ for the insulated busbar under the rated current load. The discrepancy between the simulation and test results is analyzed as follows. In Section 2.1.2, it is concluded that the absolute measurement deviation of the surface temperature without a heat insulated layer is approximately proportional to the surface temperature rise. For the insulated busbar, the surface temperature rise is mainly affected by both the solar radiation and the wind, which are not considered in the simulation model. The former factor increases the temperature rise while the latter one decreases the temperature rise, which accounts for the discrepancy. From Fig. 13 and Fig. 14b it can be noted that most of the time when the measurement 
deviation was larger than $5.7 \mathrm{~K}$ was the time when the surface temperature rise was increased by the solar radiation. On the other hand, the measurement deviation of less than $5.7 \mathrm{~K}$ was influenced by the wind outdoors, especially on the last day when it was blowy according to the weather report.

The above explanation also indicates the validation of the previous thermal analyses. In fact, it is difficult and unnecessary to obtain the exact boundary conditions in practice as the discrepancy between the test and simulation is acceptable and it will not affect the qualitative analysis.

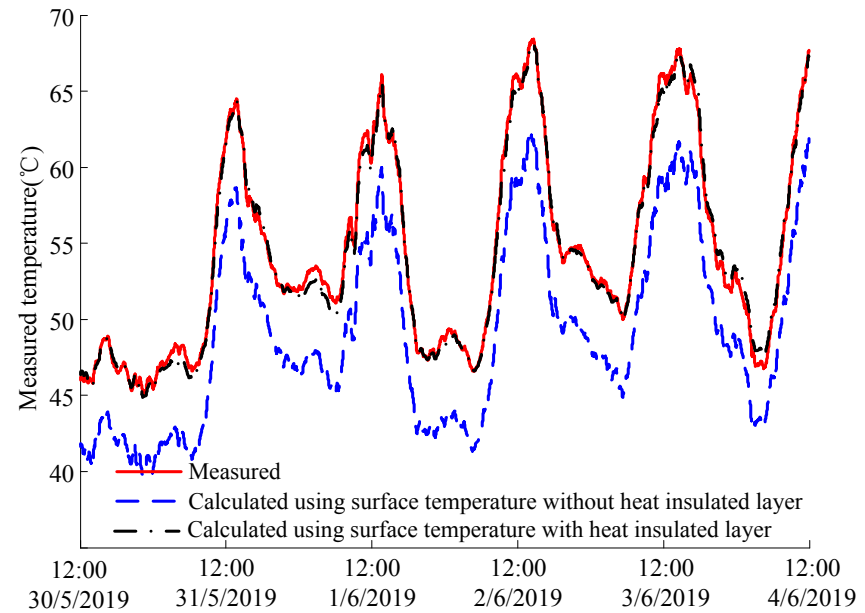

(a)

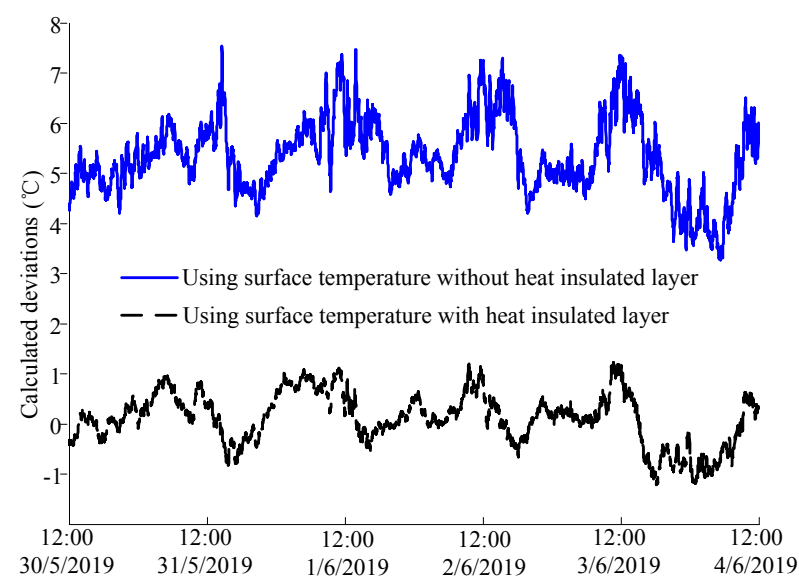

(b)

Fig. 14. Comparison of the conductor temperatures of the insulated busbar. (a) Measured and calculated results. (b) Calculated deviations.

\subsubsection{Reproducibility and uncertainty of the measurement}

According to ISO/IEC Guide 98-3:2008(E) (ISO/IEC Guide 98-3, 2008), the reproducibility means the closeness of the agreement between the results of measurements of the same measurand carried out under changed conditions of measurement. In this paper, the reproducibility can be regarded as the consistency of the surface temperature measurement under different environmental conditions.

The above temperature rise test was carried out in the summer. To express the reproducibility, another test was performed in the winter, and the current was also constant, 1350 A throughout the test. The test results are shown in Fig. 15. It can be seen that the calculated conductor temperature using surface temperature with heat insulated layer is in good agreement with the measured conductor temperature, which indicates a good reproducibility of these data.

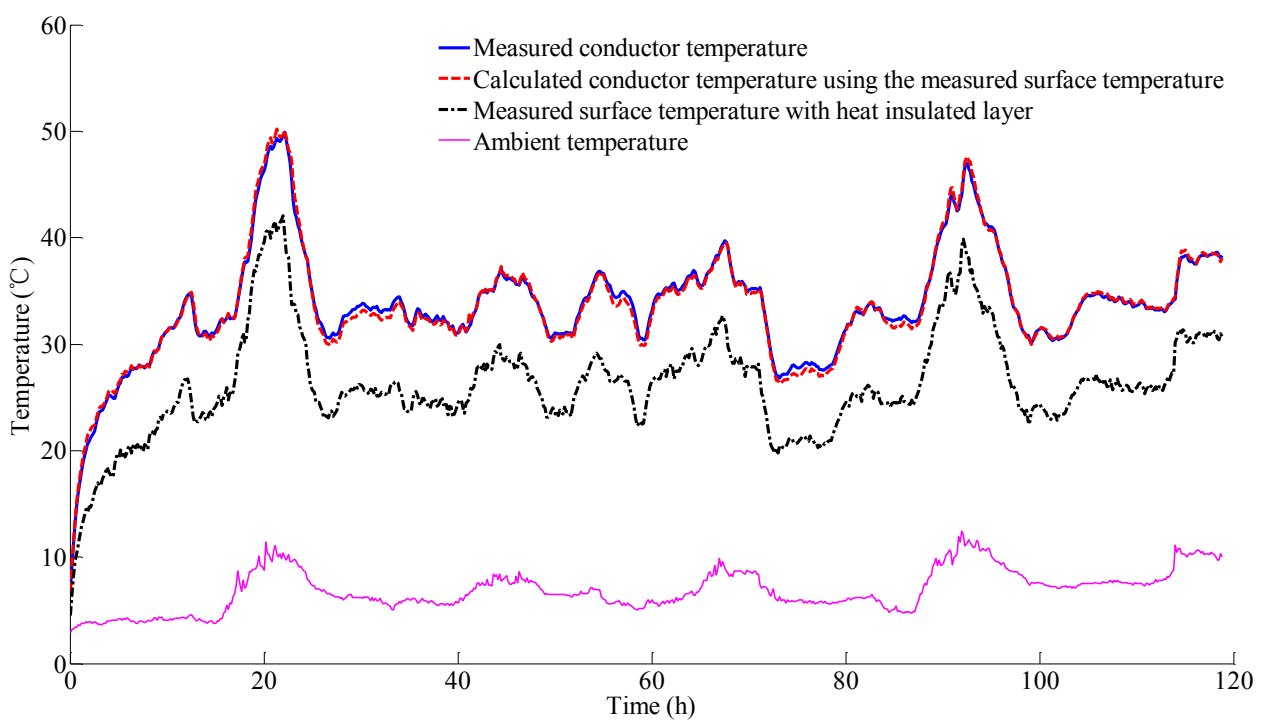

Fig. 15. The measured temperatures and calculated temperature in the winter to check the reproducibility. 
The uncertainty of measurement is defined to be a parameter, associated with the result of a measurement, that characterizes the dispersion of the values that could reasonably be attributed to the measurand (ISO/IEC Guide 98-3, 2008). The parameter could be a standard deviation, which is called standard uncertainty. However, the standard deviation is only suitable for stable data not the dynamic surface temperature. Therefore, it is necessary to transform the dynamic surface temperature into the stationary stochastic data. The standard deviation or standard uncertainty of the processed data after moving the trend components is calculated to be about $0.35 \mathrm{~K}$.

\subsection{Varying load current}

In order to illustrate the effect of the change of the load current on the surface temperature measurement, another temperature rise test under varying current was also performed. The current is given in Fig. 16 and the temperature is shown in Fig. 17. It is concluded from these figures that the calculated conductor temperature by the measured surface temperature agrees well with the measured conductor temperature even under varying current.

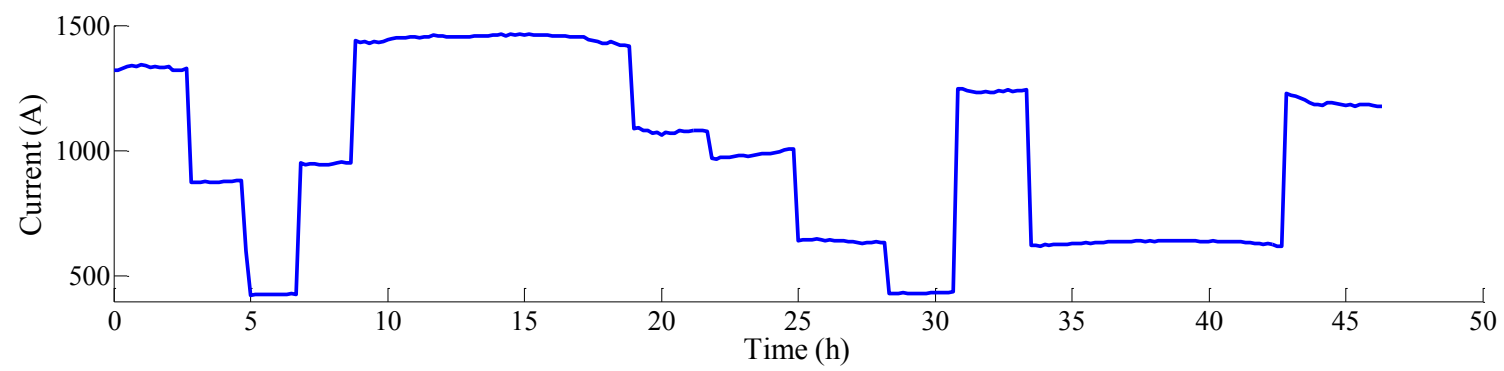

Fig. 16. The change of the current with the time.

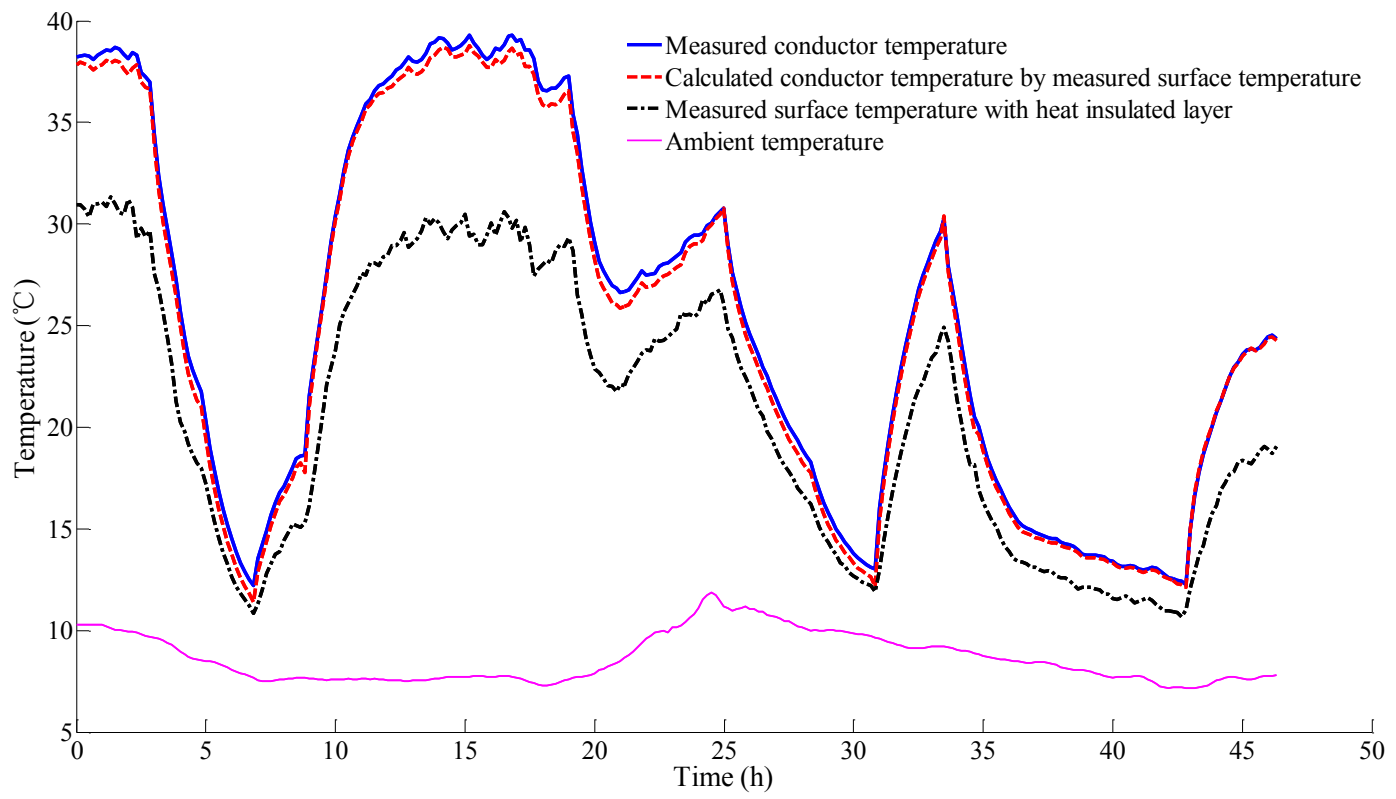

Fig. 17. The measured temperatures and calculated temperature during the test under varying current.

\subsection{Generalization of the method to DTS}

The previous analyses are all based on the discrete temperature monitoring system. In fact, the distributed temperature sensing system (DTS) represents the major trend in cable temperature monitoring nowadays. The temperature sensor in these systems is the optical fiber sensor that replaces thousands of individual discrete-temperature measurements (IEEE Standard 1718, 2012).

In most existing and new installations, the fiber sensors could only be fixed to the outside surface of the cable or busbar. Therefore, if the cable or insulated busbar are installed in the free air, the measurement temperature will be 
definitely lower than the real value due to the effect of the ambient temperature as analyzed before. In the following passage, the heat insulated layer will be applied to the DST for the generalization of the presented method using FEM thermal analyses.

The structure and dimensions of the fiber sensor used in the simulation are sketched in Fig. 18. The optical fiber is the sensing part that provides the data to constitute the temperature profile along the entire fiber length. This fiber sensor incorporates two single-mode cores and two multi-mode cores drawn into a stainless steel tube protected against corrosion by a PE jacket.

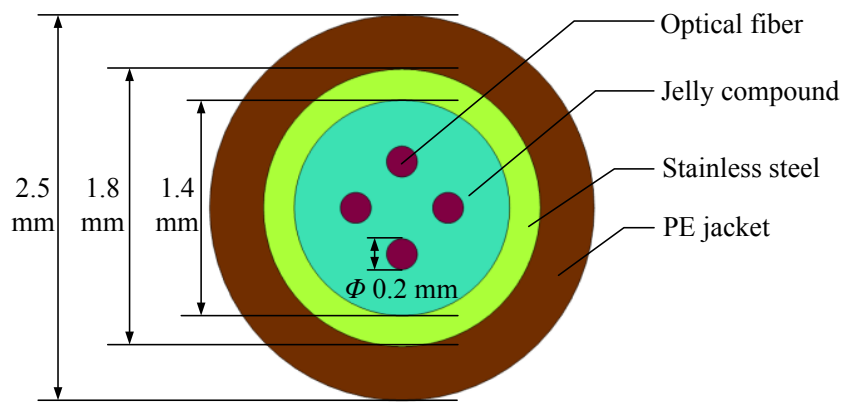

Fig. 18. The section view of the fiber sensor.

The material property of the PE jacket is the same as that of the XLPE oversheath in Table 1. The thermal conductivity of the stainless steel is $15 \mathrm{~W} /(\mathrm{m} \bullet \mathrm{K})$ and the optical fiber is mainly composed of the silicon dioxide, of which the thermal conductivity is $1.38 \mathrm{~W} /(\mathrm{m} \bullet \mathrm{K})$ (Gengel, 2008). The thermal conductivity of the jelly compound is actually unknown, but according to the FEM thermal analysis, it is found that different thermal conductivities hardly affect the temperature profile. As a result, its thermal conductivity is arbitrarily set to $1 \mathrm{~W} /(\mathrm{m} \bullet \mathrm{K})$ in this paper.

In the first FEM thermal analysis, the fiber sensor is assumed to be attached to the surface of the insulated busbar without a heat insulated layer. A 2-D plane model is adopted here for simulation due to the sufficient length of the fiber sensor. The other conditions are identical to that described previously. The simulation results are given in Fig. 19.

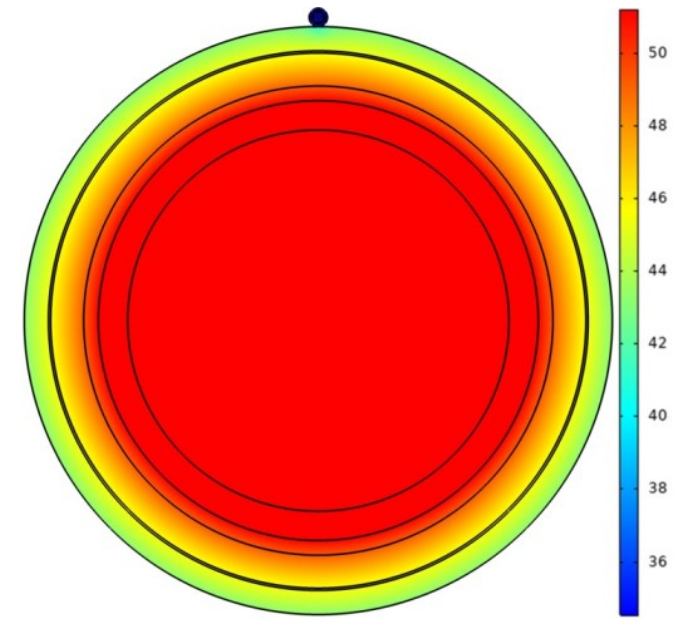

(a)

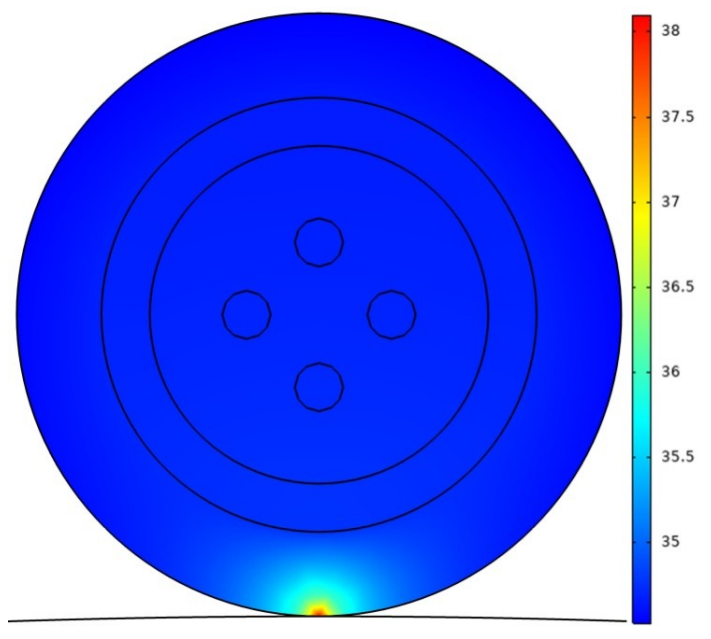

(b)

Fig. 19. The temperature profile of the insulated busbar laid with the fiber sensor. (a) Overall temperature. (b) Temperature of the fiber sensor.

It can be observed from Fig. 19 that the temperature of the inner optical fiber is only about $34.7^{\circ} \mathrm{C}$, which is $8.7 \mathrm{~K}$ lower than the surface temperature of the busbar. This measurement deviation is even larger than that of platinum resistance thermometer, which reveals the significance of improving the surface temperature measurement in DTS. The large deviation is caused by the fact that the fiber sensor is not isothermal due to the low thermal conductivity in PE jacket. For this reason, the contact portion between the busbar surface and the sensor is hotter than the inner optical fiber, thus resulting in a lower measured temperature in the fiber sensor. 
In the same way used for the platinum resistance thermometer, a heat insulated layer is adopted here to cover the fiber sensor for the improvement of the surface measurement. By means of the trial-and-error method, the thickness and the coverage angle of the heat insulated layer are optimized to be $4 \mathrm{~mm}$ and $30^{\circ}$, respectively. The temperature profiles of the insulated busbar are illustrated in Fig. 20.

It could be noticed from Fig. 20 that the temperature of the inner optical fiber is nearly $43.3^{\circ} \mathrm{C}$, much closer to the real surface temperature $43.4^{\circ} \mathrm{C}$. This study demonstrates that the precision of surface temperature measurement using DST could be markedly improved by means of the heat insulated layer.

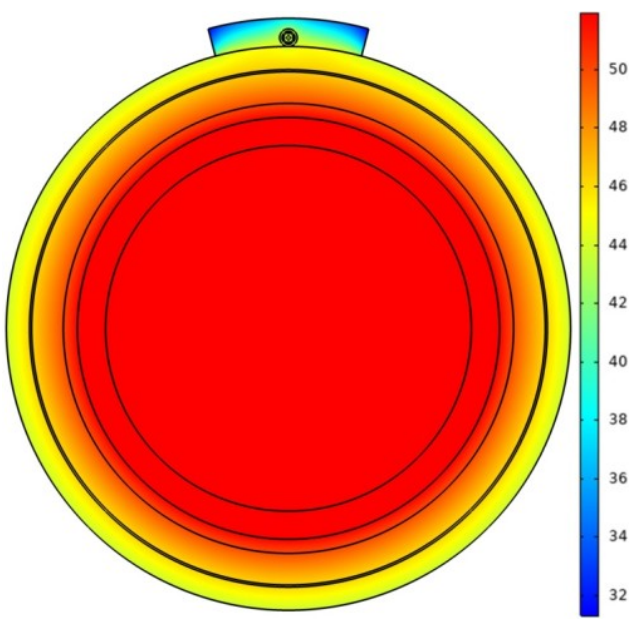

(a)

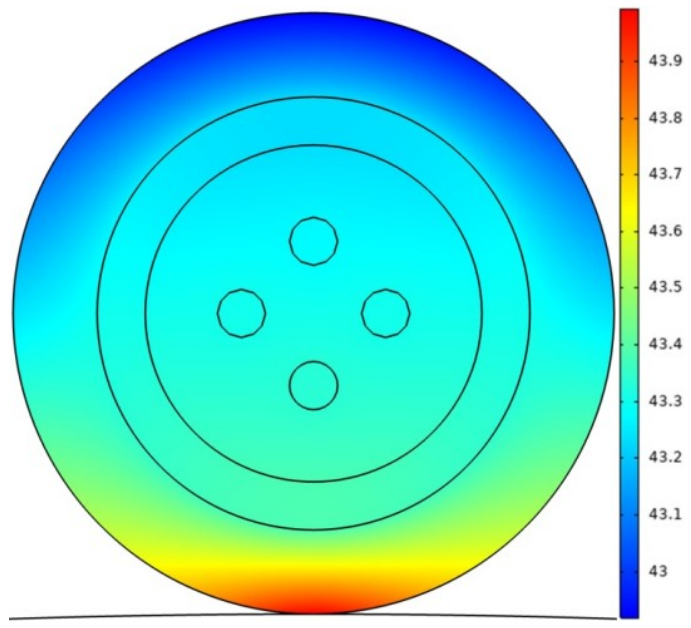

(b)

Fig. 20. The temperature profile of the insulated busbar laid with the fiber sensor covered by a heat insulated layer. (a) Overall temperature. (b) Temperature of the fiber sensor.

To prove that the presented method can also accurately measure the temperature distribution in the axial direction with a local temperature change, a three-dimensional model for the busbar laid with the fiber sensor covered by a heat insulated layer was set up in Comsol. This model is generated by extruding the area in Fig. 20 and the heat generation rate of the conductor in the middle part is set to twice that of the normal conductor to simulate the local heating. The comparison of the axial temperature distribution between the surface and the fiber sensor is shown in Fig. 21. It can be seen that the temperature deviation is no more than $0.05 \mathrm{~K}$, which demonstrates that the proposed method can accurately measure the temperature distribution in the axial direction if with a local temperature change.

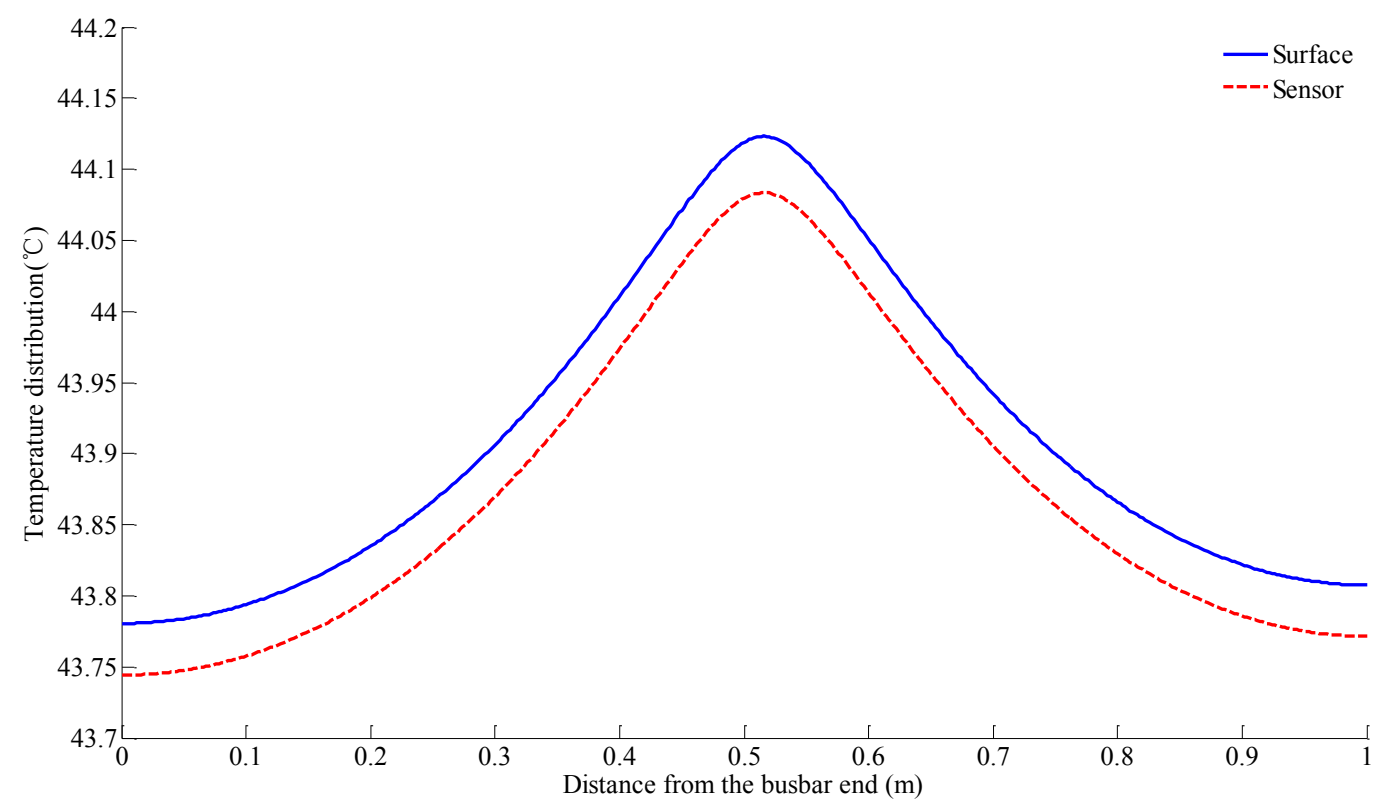

Fig. 21. The comparison of the axial temperature distribution between the surface and the fiber sensor. 


\section{Conclusions}

In this paper, the surface temperature measurements of both the power cable and the insulated busbar are improved by wrapping a heat insulated layer around the temperature sensor. The main conclusions are summarized as follows:

(1) The 3-D FEM thermal analyses are carried out on the insulated busbar and the cable laid with the platinum resistance thermometer. The results demonstrate that the temperatures of the sensors in the insulated busbar and the cable are lower than the actual surface temperature by about $5.7 \mathrm{~K}$ and $3.4 \mathrm{~K}$, respectively. It is found that the absolute measurement deviation of the surface temperature is nearly proportional to the surface temperature rise.

(2) When the optimized heat insulated layer is wrapped around the platinum resistance thermometer in the simulation model, the measurement deviation is almost zero.

(3) The temperature rise test of the insulated busbar was performed, in which the conductor temperature and surface temperatures with and without the heat insulated layer were measured. The conductor temperatures were calculated using the two different measured surface temperatures for verification. By comparison with the measured conductor temperature, the deviation of the surface temperature measurement without the heat insulated layer is about $4 \sim 7 \mathrm{~K}$ while that with the heat insulated layer is nearly $\pm 1 \mathrm{~K}$.

(4) The 2-D FEM thermal analysis is carried out on the insulated busbar laid with the fiber sensor, where the temperature of the optical fiber is $8.7 \mathrm{~K}$ lower than the real surface temperature. After the fiber sensor is covered by the heat insulated layer with the thickness of $4 \mathrm{~mm}$ and the coverage angle of $30^{\circ}$, the measurement deviation is significantly reduced.

\section{Nomenclature}

$g$-gravitational acceleration, $\left[\mathrm{ms}^{-2}\right]$

$h$-convective heat transfer coefficient, $\left[\mathrm{Wm}^{-2} \mathrm{~K}^{-1}\right]$

$L$-diameter of the cylinder, [m]

Pr -Prandtl number of air

Ra-Rayleigh number

$T_{\mathrm{w}}$-surface temperature, $[\mathrm{K}]$

$T_{\infty}$-ambient temperature, [K]

$R_{\mathrm{e}}$-external thermal resistance, $[\mathrm{K} / \mathrm{W}]$

$R_{\mathrm{h}}$-thermal resistance of heat insulated layer, [K/W]

$R_{\mathrm{i}}$-insulation thermal resistance, [K/W]

\section{Greek symbols}

$\beta$-coefficient of volume expansion, $\left[\mathrm{K}^{-1}\right]$

$\varepsilon$-emissivity of the surface

$\lambda$-thermal conductivity of air, $\left[\mathrm{Wm}^{-1} \mathrm{~K}^{-1}\right]$

$v$-kinematic viscosity of the air, $\left[\mathrm{Wm}^{-2} \mathrm{~K}^{-4}\right]$

$\sigma$-Stefan-Boltzman constant, $\left[\mathrm{Wm}^{-2} \mathrm{~K}^{-4}\right]$

\section{Acknowledge}

The authors would like to thank Hubei Xinghe Electric Power New Material Co., Ltd., who provided and assembled the insulated busbar.

\section{References}

Blumm, J., Lindemann, A., Meyer, M. and Strasser, C., Characterization of PTFE using advanced thermal analysis techniques, International Journal of Thermophysics, Vol.31, No.10 (2010), pp.1919-1927.

Dellinger, J.H., The temperature coefficient of resistance of copper, Journal of the Franklin Institute, Vol.170, No.3 (1910), pp.213-216.

Gengel, Y.A., Introduction to Thermodynamics and Heat Transfer (2008), McGraw-Hill.

Hu, X.M., Liang, L.X., Tan, Z.R., Zhang, L., Li, J.H. and Li, Y.M., The partial discharge characteristics study of the insulated copper busbar joint metal metal protrusion defect, Advanced Materials Research, Vol.614, (2013), pp.1126-1130.

IEC 60287-1-3, Calculation of the continuous current ratings of cables (100\% load factor), (1982).

IEC 60751, Industrial Platinum Resistance Thermometers and Platinum Temperature Sensors, (2016).

IEC 60853-2, Calculation of the Cyclic and Emergency Rating of Cables, (1989). 
IEEE Standard 1718, IEEE guide for temperature monitoring of cable systems, (2012).

ISO/IEC Guide 98-3, Uncertainty of measurement, part 3: guide to the expression of uncertainty in measurement, (2008)

Jones, S., Bucea, G., McAlpine, A., Nakanishi, M., Mashio, S., Komeda, H. and Jinno, A., Condition monitoring system for TransGrid $330 \mathrm{kV}$ power cable, IEEE International Conference on Power System Technology (2004), pp.1282-1287.

Li, C.L., Liu, R., Li, P.H., Li, W.P., Gao, N.K., Electric field simulation of typical defects in the epoxy/paper composites insulated tubular bus, Materials Science Forum, Vol.922, (2018), pp.157-162.

Li, H.J., Tan, K.C. and Su. Q., Assessment of underground cable ratings based on distributed temperature sensing, IEEE Transactions on Power delivery, Vol.21, No.4 (2006), pp.1763-1769.

Li, P.H., Ruan, L., Li, C.L., Yang, F., Jin, H.Y. and Zhu, S.R., Optimization for epoxy/paper composites insulated tubular bus structure, Materials Science Forum, Vol.922, (2018), pp.169-174.

Millar, R.J. and Lethonen. M., A robust framework for cable rating and temperature monitoring, IEEE Transactions on Power delivery, Vol.21, No.1 (2005), pp.313-321.

Niu, H.Q., Yu, J. and Ye, K.F., Calculation of transient cable conductor temperature based on support vector machine optimized by particle swarm optimization algorithm, IEEE International Conference on High Voltage and Application (2016), pp.1-5.

Price, D.M. and Jarratt. M., Thermal conductivity of PTFE and PTFE composites, Thermochimica Acta, Vol.392, No.2 (2002), pp.231-236.

Swingler, S.G. and Holte, T.A., Direct and indirect assessment of temperature in HV cables, International Conference on Large High Voltage Electric Systems (1994), pp.2-3.

Tanaskovic, M.R., Calculation of the ampacity of high voltage cables laid in free air, Tehnika, Vol.73, No.1 (2018), pp.89-98.

Yang, L., Qiu W.H., Huang, J.C., Hao, Y.P., Fu, M.L., Hou, S. and Li, L.C., Comparison of conductor-temperature calculations based on different radial-position-temperature detections for high-voltage power cable, Energies, Vol.11, No.1 (2018), pp.117. 